\title{
BIOMIMETIC OXIDATION OF CARBAMAZEPINE WITH HYDROGEN PEROXIDE CATALYZED BY A MANGANESE PORPHYRIN
}

Cláudia M. B. Neves, Mário M. Q. Simões*, Fernando M. J. Domingues, M. Graça P. M. S. Neves e José A. S. Cavaleiro

Departamento de Química, QOPNA, Universidade de Aveiro, 3810-193 Aveiro, Portugal

Recebido em 26/10/11; aceito em 25/1/12; publicado na web em 15/6/12

\begin{abstract}
This laboratory project is planned for an undergraduate chemistry laboratory in which students prepare a manganese porphyrin able to mimic the oxidative metabolism of carbamazepine, one of the most frequently prescribed drugs in the treatment of epilepsy. The in vitro oxidation of carbamazepine results in the formation of the corresponding 10,11-epoxide, the main in vivo metabolite. The reaction is catalyzed by manganese porphyrin in the presence of $\mathrm{H}_{2} \mathrm{O}_{2}$, an environmentally-friendly oxidant. Through this project students will develop their skills in organic synthesis, coordination chemistry, chromatographic techniques such as TLC and HPLC, UV-visible spectrophotometry, and NMR spectroscopy.
\end{abstract}

Keywords: Mn(III) porphyrin; catalysis; epoxidation.

\section{INTRODUCTION}

Epoxides are very easy to prepare via the reaction of an alkene with a peroxy acid and epoxide chemistry is routinely discussed in organic chemistry manuals. ${ }^{1}$ In addition, it seems that metalloporphyrins as catalysts and hydrogen peroxide as an oxidant have not yet been utilized in epoxidation reactions for undergraduate teaching laboratories. The developments achieved recently for epoxidation catalyzed by metalloporphyrins make this an appealing system from a synthetic point of view. ${ }^{2}$

This lab project is intended for a fifth semester laboratory of the BSc Chemistry course, with weekly sessions of $8 \mathrm{~h}$. Normally, students who enrol in this laboratory have already attended 2 semesters of organic chemistry and 1 semester of a practical organic chemistry course. In this lab project, which is planned for three $8 \mathrm{~h}$ sessions, students (in groups of 2) will set up a non-enzymatic system able to mimic the oxidative metabolism of carbamazepine (3), one of the most frequently prescribed drugs in the treatment of epilepsy. ${ }^{3}$

The metabolism of drugs and other xenobiotics is often initiated by oxidation reactions catalyzed by cytochrome P450 (CYP) enzymes. ${ }^{4}$ Since the isolation of the biological entities can become complicated and time-consuming, synthetic models have been developed for mimicking the role of CYP in living organisms. In fact, there are several synthetic models that can mimic, in vitro, the role of CYP, including metalloporphyrins. ${ }^{4-7}$

Students should realize the importance and the potentiality of metalloporphyrins as biomimetic chemical models in the research and development of biologically active molecules, along with the prediction of oxidation metabolites that can allow a better understanding of drugs' mechanism of action. This is an extremely rewarding area for students of an undergraduate chemistry laboratory because it introduces students to the synthesis and characterization of porphyrins and their manganese complexes, allowing the use of chromatographic and spectroscopic techniques, and the assessment of the performance of a catalyst, namely based on percent conversion, selectivity and turnover number (TON).

For this purpose, students will prepare and use the manganese(III) complex of 5,10,15,20-tetrakis(2,6-dichlorophenyl)porphyrin [Mn(TDCPP)Cl] (2), an extensively studied catalyst in oxidation

*e-mail: msimoes@ua.pt processes, mimicking a wide range of reactions catalyzed by CYP enzymes. ${ }^{8}$ The oxidation reaction of carbamazepine (3) using $\mathrm{Mn}$ (TDCPP)Cl results in the formation of the epoxide (4), known as its main in vivo metabolite, and involves chromatographic techniques such as TLC and HPLC, allowing students to follow up the reaction and to observe the formation of the epoxide along with the disappearance of the substrate. The epoxide will subsequently be characterized by ${ }^{1} \mathrm{H}$ NMR spectroscopy. In this reaction diluted aqueous hydrogen peroxide, a safe, easily available and environmentally-friendly oxidant is used. When hydrogen peroxide is chosen as an oxidant for catalytic processes, its dismutation reaction must be taken into account and an excess of oxidant should be used. ${ }^{9,10}$

\section{EXPERIMENTAL}

TLC silica gel plastic sheets (with $\mathrm{F}_{254}$ indicator and without indicator) and manganese(II) chloride were purchased from Merck. Ammonium acetate and 2,6-dichlorobenzaldehyde were obtained from Fluka, whereas pyrrole and carbamazepine were obtained from SigmaAldrich. Hydrogen peroxide $30 \%$ (w/w) was purchased from Riedel-de Haën and HPLC grade acetonitrile was obtained from LabScan.

UV-visible analyses were performed on a Uvikon 922 spectrophotometer and HPLC analyses were carried out using a Gilson model 321 instrument equipped with a UV/Vis-156 Gilson detector and a Waters Spherisorb S10 ODS2 (10 $\mu \mathrm{m})$ reversed-phase column. Organic compounds were analyzed by ${ }^{1} \mathrm{H}$ NMR (Bruker Avance 300 spectrometer at $300.13 \mathrm{MHz}$ ), using $\mathrm{CDCl}_{3}$ as the solvent and TMS as the internal reference.

The synthesis (monitored by TLC and UV-vis) of the free-base 5,10,15,20-tetrakis(2,6-dichlorophenyl)porphyrin (1) is carried out during the first lab session; the second lab session involves the filtration and characterization of (1) (by ${ }^{1} \mathrm{H}$ NMR) and the synthesis of the manganese(III) complex (2) (monitored by TLC and UV-vis); the third session involves the catalytic oxidation of carbamazepine, including monitorization of the reaction by TLC, HPLC and also includes ${ }^{1} \mathrm{H}$ NMR characterization of the epoxide.

The synthesis of the porphyrin catalyst involves two steps. In an initial step, the 5,10,15,20-tetrakis(2,6-dichlorophenyl)porphyrin (1) is synthesized by a methodology that involves the condensation of pyrrole with 2,6-dichlorobenzaldehyde in a mixture of acetic acid and nitrobenzene at $120{ }^{\circ} \mathrm{C}$ (Scheme 1a). ${ }^{11}$ 


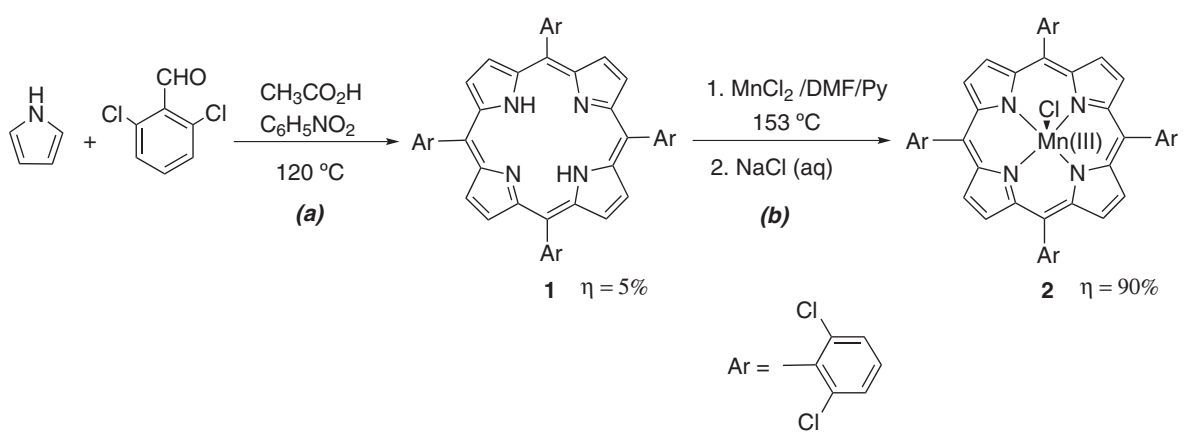

Scheme 1. Synthesis of the manganese porphyrin catalyst

The synthesis of the manganese(III) complex (2) is then performed by the reaction of the free-base porphyrin with $\mathrm{MnCl}_{2}$ under reflux in DMF (Scheme 1b). ${ }^{12}$

Subsequently, students carry out the carbamazepine oxidation reaction using $\mathrm{Mn}(\mathrm{TDCPP}) \mathrm{Cl}$ (2) as the catalyst, ammonium acetate as the co-catalyst and hydrogen peroxide as the oxidant (diluted 1:5 in acetonitrile) in an initial total volume of $2.0 \mathrm{~mL}$ of acetonitrile at 25-30 ${ }^{\circ} \mathrm{C}$ (Scheme 2). The $\mathrm{H}_{2} \mathrm{O}_{2}$ additions (aliquots of $0.05 \mathrm{mmol}$ ) are made every $15 \mathrm{~min}$ during the reaction. Different substrate/ catalyst molar ratios $(150,300$ and 600$)$ can be used, by different student groups, in order to compare the influence of the amount of catalyst added.
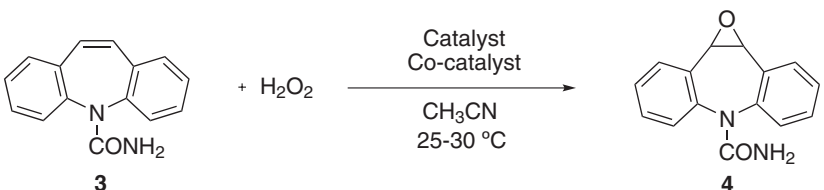

Scheme 2. Catalytic oxidation of carbamazepine (3)

The reaction can be followed by TLC and by reverse-phase HPLC, monitoring the formation of epoxide (4) and the disappearance of carbamazepine (3). The liquid-liquid extraction of the reaction mixture with dichloromethane, followed by solvent removal will provide a sufficiently pure epoxide sample to be characterized by ${ }^{1} \mathrm{H}$ NMR.

\section{Session 1. Synthesis of 5,10,15,20-tetrakis(2,6-dichlorophenyl) porphyrin (1)}

In a two-neck round bottom flask (1000 mL), equipped with a reflux condenser and a dropping funnel, mix $105 \mathrm{~mL}$ of glacial acetic acid and $75 \mathrm{~mL}$ of nitrobenzene (flasks with bottle-top dispensers should be used for safety reasons). Place the mixture on a heating oil bath at $120{ }^{\circ} \mathrm{C}$, with stirring, and add the 2,6-dichlorobenzaldehyde $(6.3 \mathrm{~g}, 28.8 \mathrm{mmol})$. After complete dissolution of the aldehyde, slowly add the pyrrole $(2.00 \mathrm{~mL}, 28.8 \mathrm{mmol})$ through the dropping funnel (the addition of pyrrole should be carried out only when the reaction mixture is at reflux) and leave the reaction under reflux for $45 \mathrm{~min}$.

The reaction can be followed by TLC (a brown spot can be observed in the front of the solvent using $\mathrm{CH}_{2} \mathrm{Cl}_{2}$ as eluent; Figure $1 \mathrm{~S}$, supplementary material) and by UV-Visible spectrophotometry. Figure 1a shows the typical UV-Vis spectrum of 5,10,15,20-tetrakis(2,6-dichlorophenyl) porphyrin (1) at the end of the reaction, where a strong Soret band can be observed at $417 \mathrm{~nm}$, along with three $\mathrm{Q}$ bands. The absorption spectrum of free-base porphyrins shows a typical absorption band of high intensity at around $420 \mathrm{~nm}$, which is called the Soret band, and two to four bands (I, II, III, IV) between $480-700 \mathrm{~nm}$, called the Q bands. The Soret band is common to all macrocycles. ${ }^{13,14}$

After cooling, the porphyrin can be crystallized directly from the reaction medium by the addition of $200 \mathrm{~mL}$ of methanol. Place the
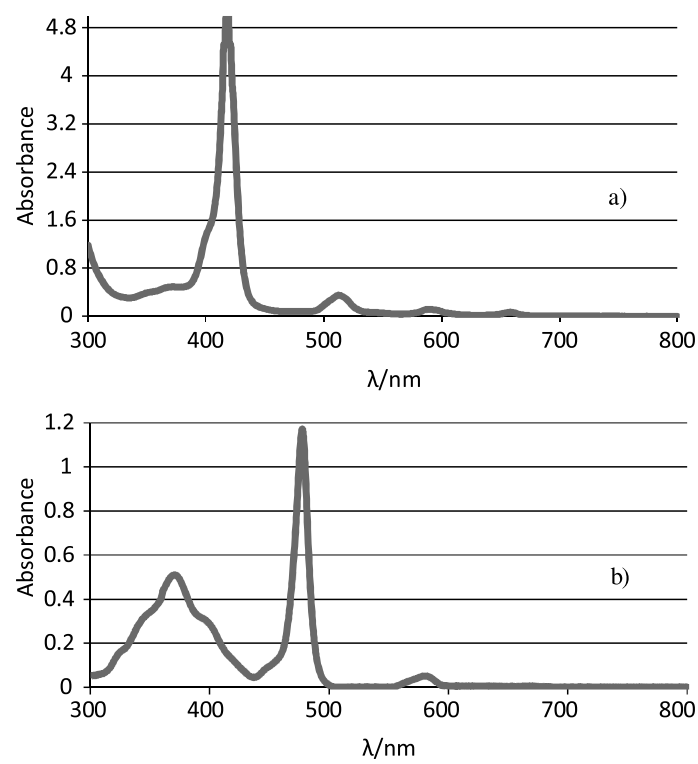

Figure 1. Typical UV-Vis spectra of a) 5,10,15,20-tetrakis(2,6-dichlorophenyl)porphyrin $\left.\left(\mathrm{H}_{2} \mathrm{TDCPP}\right)(1) ; b\right)$ manganese $(I I)$ complex of 5,10,15,20-tetrakis(2,6-dichlorophenyl)porphyrin [Mn(TDCPP)Cl] (2)

reaction flask in a recipient with ice and let it stand in the dark as the product precipitates. Two hours should suffice to observe the formation of a powder, which must then be filtered through a normal glass funnel with cotton wool, recovering the mother liquor in a $1000 \mathrm{~mL}$ round-bottom flask (if kept for the next session, the mother liquor should provide another crop of crystals). Wash the cotton wool with methanol to remove the black tars and then dissolve the purple porphyrin retained in the cotton wool with dichloromethane into a clean round bottom flask $(250 \mathrm{~mL})$. Evaporate the solvent in a rotary evaporator, dissolve the residue in a minimal amount of dichloromethane and add methanol (about $50 \mathrm{~mL}$ ) to crystallize the porphyrin. Leave this solution protected from light until the next session.

Students should finish this session with the recrystallization step. The crystals should be filtered and then dried in an oven $\left(60^{\circ} \mathrm{C}\right)$ at the beginning of the following session, while students prepare the assembly for the following reaction.

\section{Session 2. Characterization of (1) and synthesis of the manganese(III) complex (2)}

Filter the free-base porphyrin (1) crystals left to crystallize at the end of session 1, under vacuum, in a Hirsch funnel with filter paper. Wash the purple crystals 2-3 times with methanol (10 mL). Place the crystals in an oven $\left(60^{\circ} \mathrm{C}\right)$ to dry for about $1 \mathrm{~h}$. Porphyrin structure can then be confirmed by ${ }^{1} \mathrm{H}$ NMR $\left(\mathrm{CDCl}_{3}\right)$.

The ${ }^{1} \mathrm{H}$ NMR spectrum of (1) presents the typical three signals of 
the symmetrical 5,10,15,20-tetraaryl substituted porphyrins (Figure $2 \mathrm{~S}$, supplementary material): a singlet at $\delta-2.54 \mathrm{ppm}$, corresponding to the NH protons; a singlet at $\delta 8.67 \mathrm{ppm}$ corresponding to the eight pyrrole protons; a multiplet at $\delta 7.67-7.81 \mathrm{ppm}$, corresponding to the twelve aromatic protons of the 5,10,15,20-tetraaryl substituents.

Into a $25 \mathrm{~mL}$ round bottom flask, equipped with a reflux condenser and a magnetic bar, weigh $50 \mathrm{mg}(0.1 \mathrm{mmol})$ of porphyrin (1) and dissolve it in $5.0 \mathrm{~mL}$ of DMF. Reflux the solution in the dark, under a nitrogen atmosphere and add $0.5 \mathrm{~mL}$ of pyridine and 10 eq. (198 $\mathrm{mg} ; 1 \mathrm{mmol})$ of manganese(II) chloride $\left(\mathrm{MnCl}_{2} \cdot 4 \mathrm{H}_{2} \mathrm{O}\right)$.

Monitor the progress of the reaction by UV-Vis and by TLC (a new red spot of (2) can be observed at the base, in contrast with the brown spot of (1) at the top of the TLC plate, using $\mathrm{CH}_{2} \mathrm{Cl}_{2}$ as eluent; Figure $3 \mathrm{~S}$, supplementary material). The UV-Vis spectrum shows a Soret band shift to a higher wavelength $\left(\lambda_{\max }=478 \mathrm{~nm}\right)$ and the disappearance of two $\mathrm{Q}$ bands of the free-base macrocycle, thereby confirming the presence of the complex (Figure 1b). The transition band of manganese at $\lambda_{\max } 371 \mathrm{~nm}$ can also be observed. The reaction normally takes $2 \mathrm{~h}$ to be complete.

Turn off the heat and keep the reaction mixture under stirring for around $30 \mathrm{~min}$, in the open air and protected from light. Remove the solvent in the rotary evaporator and dissolve the residue in dichloromethane. As DMF has a very high boiling point $\left(153{ }^{\circ} \mathrm{C}\right)$, addition of a small amount of toluene will facilitate solvent removal. Wash the organic phase 2-3 times with water in a separating funnel, and finally with a saturated sodium chloride solution. Filter the organic phase through a glass funnel with cotton wool, and anhydrous sodium sulfate into a round bottom flask $(100 \mathrm{~mL})$, remove the solvent in the rotary evaporator and then crystallize the residue in hexane, after dissolution in a minimal amount of dichloromethane.

The crystals thus formed should then be filtered under vacuum, using a Hirsch funnel with filter paper, washed several times with hexane and placed in an oven $\left(60^{\circ} \mathrm{C}\right)$ to dry for about $1 \mathrm{~h}$. The yield, based on the porphyrin, should be over $90 \%$.

This session should end with the crystallization step. Filtration and drying of the crystals should be done in the next session, in order to maximize the yield.

\section{Session 3. Oxidation of carbamazepine}

Prepare the catalyst (2) stock solution by dissolving $10 \mathrm{mg}$ of (2) in a $10 \mathrm{~mL}$ volumetric flask, with a small amount of acetonitrile (if necessary, use ultrasound to help dissolve the catalyst), and then fill it to the $10 \mathrm{~mL}$ mark. Prepare the oxidant solution by diluting $1.0 \mathrm{~mL}$ of $\mathrm{H}_{2} \mathrm{O}_{2} 30 \%$ (w/w) with $\mathrm{CH}_{3} \mathrm{CN}$ in a $5 \mathrm{~mL}$ volumetric flask.

In a pear-shaped flask of 10 or $25 \mathrm{~mL}$, add $0.1 \mathrm{mmol}$ of carbamazepine $(23.6 \mathrm{mg})$, the required volume of the catalyst stock solution (variable according to the substrate/catalyst molar ratio used), $15 \mathrm{mg}$ of ammonium acetate (the co-catalyst), and acetonitrile until attaining a reaction mixture final volume of $2 \mathrm{~mL}$. Keep the reaction mixture under stirring at $25-30{ }^{\circ} \mathrm{C}$ and protected from light. Add $25 \mu \mathrm{L}(0.05$ $\mathrm{mmol}$ ) of the oxidant-diluted solution at regular intervals of $15 \mathrm{~min}$.

Take a $10 \mu \mathrm{L}$ aliquot from the reaction mixture before each oxidant addition and dilute the aliquot with $2 \mathrm{~mL}$ of acetonitrile. The reaction can be monitored by TLC (silica gel plastic sheets with $\mathrm{F}_{254}$ indicator; Figure 4S, supplementary material) using ethyl acetate as the eluent $\left(\mathrm{Rf}_{\text {carbamazepine }}=0.25\right.$ and $\left.\mathrm{Rf}_{\text {epoxide }}=0.18\right)$, and by reversephase $\mathrm{HPLC}\left(\mathrm{CH}_{3} \mathrm{CN} / \mathrm{H}_{2} \mathrm{O}(40: 60), \lambda=215 \mathrm{~nm}\right.$, flow rate $1.0 \mathrm{~mL} / \mathrm{min}$, room temperature). The HPLC chromatogram of carbamazepine oxidation after 45 min of reaction is shown as an example in Figure 2.

Add water $(2 \mathrm{~mL})$ to the reaction mixture and extract twice with $2 \mathrm{~mL}$ of dichloromethane. Filter the organic phase through a glass funnel with cotton wool and anhydrous sodium sulfate into a

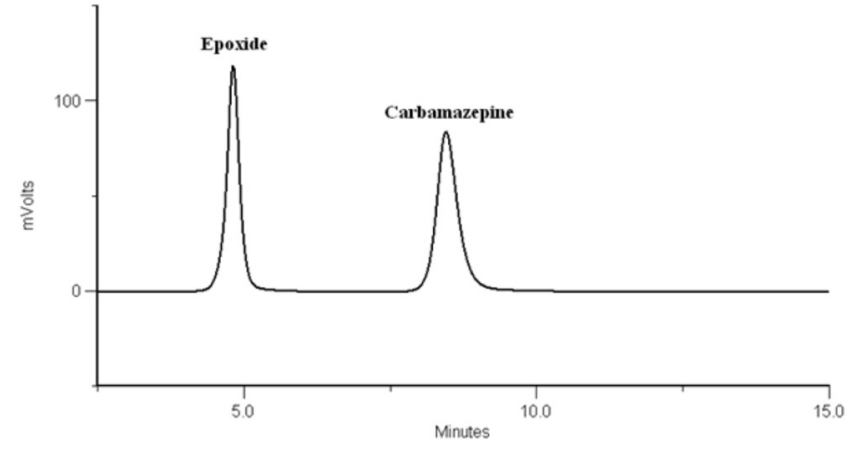

Figure 2. Reverse-phase HPLC chromatogram of carbamazepine oxidation reaction after $45 \mathrm{~min}$

round bottom flask ( 25 or $50 \mathrm{~mL}$ ). Evaporate the solvent in a rotary evaporator. Since the product resulting from the oxidation of carbamazepine is an epoxide, it is advisable to use the water bath at room temperature to evaporate the solvent in order to prevent the epoxide ring from opening. Characterize the product by ${ }^{1} \mathrm{H}$ NMR using the entire residue. The carbamazepine ${ }^{1} \mathrm{H}$ NMR spectrum should also be obtained for comparison with the final residue ${ }^{1} \mathrm{H}$ NMR spectrum.

The ${ }^{1} \mathrm{H}$ NMR spectra of carbamazepine (3) and carbamazepine 10,11-epoxide (4) are depicted in Figure 5Sa and b, supplementary material, respectively. In the ${ }^{1} \mathrm{H}$ NMR spectrum of the epoxide (4) the most important feature is the strong up field shift of the $\mathrm{H}-10,11$ singlet from $\delta 6.95 \mathrm{ppm}$ in carbamazepine to $\delta 4.28 \mathrm{ppm}$ in the 10,11-epoxide.

Table 1 summarizes the main tasks for the 3 laboratory sessions described above.

Table 1. List of main tasks for the three laboratory sessions

\begin{tabular}{lll}
\hline Session 1 & Session 2 & Session 3 \\
\hline -Synthesis of (1) us- & -Filtration of (1) & -Filtration and drying \\
ing reflux & -Drying and ${ }^{\text {H NMR }}$ & of (2) \\
-TLC and UV-Visible & characterization of (1) & -Catalytic oxidation \\
spectrophotometry & -Synthesis of (2) using & of (3) \\
-Cristalization & reflux & -TLC and reverse- \\
-Filtration & -TLC and UV-Visible & phase HPLC \\
-Evaporation of the & spectrophotometry & -Liquid-liquid extrac- \\
solvent in a rotary & -Liquid-liquid extrac- & tion \\
evaporator & tion & -Evaporation of the \\
-Recrystallization & -Evaporation of the & solvent in a rotary \\
of (1) & solvent in a rotary & evaporator \\
& evaporator & - ${ }^{-H}$ NMR characteriza- \\
& -Crystallization of (2) & tion of $(\mathbf{3})$ and (4) \\
& & -Determination of the \\
& & conversion of $(\mathbf{3})$ based \\
& & on the HPLC chro- \\
& & matogram \\
\hline
\end{tabular}

\section{Hazardous}

All chemicals used in this lab project should be handled with the propera care. All of these chemicals can be considered toxic and irritant, so inhalation or any contact with skin and eyes should be avoided. Dichloromethane and nitrobenzene are considered potential carcinogens. Pyridine is flammable and may affect fertility. Glacial acetic acid is flammable, lachrymator and causes burns. Dimethylformamide exposure may result in foetal death. Aqueous $30 \%$ hydrogen peroxide is an oxidant and may cause skin and eye burns. Lab coat, safety glasses and adequate gloves are compulsory and all the experimental work should be done in a well-ventilated fumehood. Nitrobenzene and glacial acetic acid should be measured 
Table 2. Typical results for the oxidation of carbamazepine with hydrogen peroxide catalyzed by $\mathrm{Mn}(\mathrm{TDCPP}) \mathrm{Cl}^{\mathrm{a}}$

\begin{tabular}{|c|c|c|c|c|c|c|}
\hline Entry & $\begin{array}{c}\text { Substrate/catalyst } \\
\text { molar ratio }\end{array}$ & Time (min) & $\mathrm{H}_{2} \mathrm{O}_{2}(\mathrm{mmol})$ & Conversion $(\%)$ & Selectivity (\%) & TON \\
\hline 1 & 150 & 120 & 4.0 & $>99$ & $>99$ & 148 \\
\hline 2 & 300 & 180 & 6.0 & $>99$ & $>99$ & 297 \\
\hline 3 & 600 & 240 & 8.0 & 97 & $>99$ & 582 \\
\hline 4 & without catalyst & 120 & 4.0 & 0 & -- & -- \\
\hline 5 & 150 & 120 & without & 0 & -- & -- \\
\hline
\end{tabular}

aReaction conditions: $0.1 \mathrm{mmol}$ of carbamazepine, $6.7 \times 10^{-4}$ or $3.3 \times 10^{-4}$ or $1.7 \times 10^{-4} \mathrm{mmol}$ of catalyst and $15 \mathrm{mg}$ of co-catalyst (ammonium acetate) in a final total volume of $2.0 \mathrm{~mL}$ with $\mathrm{CH}_{3} \mathrm{CN}$. Aqueous $30 \%$ (w/w) $\mathrm{H}_{2} \mathrm{O}_{2}$ diluted (1:5) in $\mathrm{CH}_{3} \mathrm{CN}$ is added every 15 min of reaction, each $\mathrm{H}_{2} \mathrm{O}_{2}$ addition corresponding to a half-substrate amount $(0.05 \mathrm{mmol})$.

using an appropriate bottle-top dispenser system, minimizing risks of contact and inhalation.

\section{RESULTS AND DISCUSSION}

Figure 3 shows the typical profile for carbamazepine conversion versus time, with different substrate/catalyst molar ratios. Depending on the substrate/catalyst molar ratio used, the reaction can be considered finished when: carbamazepine is completely consumed, as observed by TLC or HPLC; no further carbamazepine conversion is observed by TLC or HPLC.

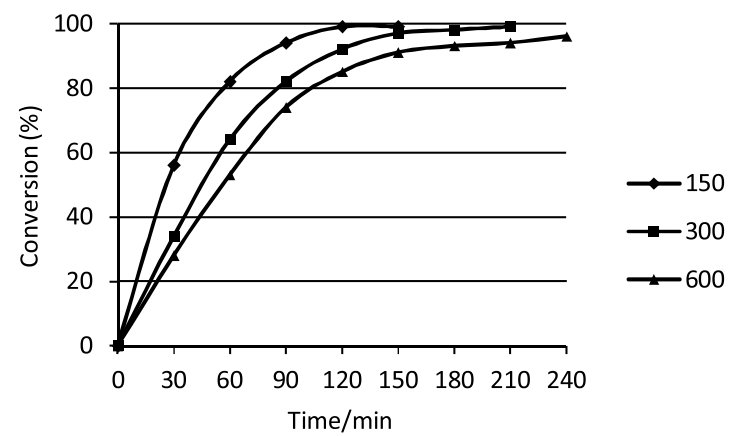

Figure 3. Carbamazepine conversion versus time, for the three molar substrate/catalyst proposed, using $\mathrm{Mn}(\mathrm{TDCPP}) \mathrm{Cl}$ as catalyst and $\mathrm{H}_{2} \mathrm{O}_{2}$ as oxidant

When a substrate/catalyst molar ratio of 150 is used, the total conversion of (3) is achieved after approximately $2 \mathrm{~h}$ of reaction. If a substrate/catalyst molar ratio of 300 is used, total conversion of (3) is achieved only after approximately $3 \mathrm{~h}$ of reaction. For a substrate/ catalyst molar ratio of 600 , the reaction is even slower and, after $4 \mathrm{~h}$ of reaction, there is no evident increase in carbamazepine conversion, as observed by HPLC (Table 1). From the ${ }^{1} \mathrm{H}$ NMR spectrum of the extracted final reaction mixture, students can identify both the epoxide and non-reacted carbamazepine, depending on the percentage of conversion of the substrate (Table 2).

\section{CONCLUSIONS}

Two main classical methods for the preparation of epoxides, namely the epoxidation of alkenes and the base-promoted ring closure of vicinal halohydrins, are commonly described in texbooks. ${ }^{1}$ However, these classical approaches produce significant amounts of waste, being certainly unacceptable in the near future, and so efforts aimed at replacing such processes by sustainable epoxidation processes are highly desirable. The synthesis of epoxides via catalyzed oxidation of alkenes represents the most elegant and environmentally friendly way for the preparation of this class of compounds. This is of particular significance, bearing in mind that the preservation of resources should be the main focus of interest when novel chemical processes are developed. Thus, the development of catalytic epoxidation methods in which hydrogen peroxide is employed as the terminal oxidant is highly attractive.

The present laboratory project aims to introduce a greener, more sustainable approach for the epoxidation of double bonds, in contrast to the current methods presented in textbooks and developed in traditional laboratory classes. Students are therefore invited to prepare an appropriate catalyst and to use a safe, easily available and environmentally friendly oxidant for the epoxidation of a highly prescribed drug via a biomimetic approach.

\section{SUPPLEMENTARY MATERIAL}

Supplementary material is available at http://quimicanova.sbq. org.br in the form of a PDF file, with free access. This material includes TLC images and ${ }^{1} \mathrm{H}$ NMR spectra of the free-base porphyrin (1), of carbamazepine (3) and of carbamazepine 10,11-epoxide (4).

\section{ACKNOWLEDGEMENTS}

Thanks are due to Fundação para a Ciência e a Tecnologia (FCT/ FEDER) for funding the Organic Chemistry Research Unit (QOPNA; Project PEst-C/QUI/UI0062/2011). Authors also acknowledge the Portuguese National NMR Network, supported with funds from FCT.

\section{REFERENCES}

1. Carey, F. A.; Organic Chemistry, $7^{\text {th }}$ ed., McGraw-Hill: New York, 2008, chap. 6; Wade, L. G.; Organic Chemistry, $3^{\text {rd }}$ ed., Prentice Hall: New Jersey, 1995, chap. 8; Vollhardt, K. P. C.; Schore, N. E.; Organic Chemistry, $3^{\text {rd }}$ ed., W. H. Freeman and Company: New York, 1998, chap. 12; Solomons, T. W. G.; Fryhle, C. B.; Organic Chemistry, $7^{\text {th }}$ ed., Wiley: New York, 2000, chap. 11; Clayden, J.; Greeves, N.; Warren, S.; Wothers, P.; Organic Chemistry, $7^{\text {th }}$ ed., Oxford University Press: New York, 2001, chap. 20.

2. Mansuy, D.; Battioni, P. In The Porphyrin Handbook; Kadish K. M.; Smith K. M.; Guilard R., eds.; Academic Press: New York, 2000, vol. 4, chap. 26; Groves J. T.; Shalyaev K.; Lee J. In The Porphyrin Handbook; Kadish K. M.; Smith K. M.; Guilard R., eds.; Academic Press: New York, 2000, vol. 4, chap. 27; Meunier B.; Robert A.; Pratviel G.; Bernadou J. In The Porphyrin Handbook; Kadish K. M.; Smith K. M.; Guilard R., eds.; Academic Press: New York, 2000, vol. 4, chap. 31.

3. Bernus, I.; Hooper, W. D.; Dickinson, R. G.; Eadie, M. J.; Epilepsy Res. 1995, 21, 65; Bernus, I.; Dickinson, R. G.; Hooper, W. D.; Eadie, M. J.; Epilepsy Res. 1996, 24, 163; Faria, A. L.; Mac Leod, T. C. O.; Assis, M. D.; Catal. Today 2008, 133, 863.

4. Lohmann, W.; Karst, U.; Anal. Bioanal. Chem. 2008, 391, 79

5. Bernadou, J.; Meunier, B.; Adv. Synth. Catal. 2004, 346, 171. 
6. Mansuy D.; C. R. Chimie 2007, 10, 392.

7. Hartmann, J.; Bartels, P.; Mau, U.; Witter, M.; van Tümpling, W.; Hofmann, J.; Nietzschmann, E.; Chemosphere 2008, 70, 453.

8. Sheldon, R. A.; Metalloporphyrins in Catalytic Oxidations, Marcel Dekker: New York, 1994; Neves, C. M. B.; Simões, M. M. Q.; Santos, I. C. M. S.; Domingues, F. M. J.; Neves, M. G. P. M. S.; Paz, F. A. A.; Silva, A. M. S.; Cavaleiro J. A. S.; Tetrahedron Lett. 2011, 52, 2898; Simões, M. M. Q.; De Paula, R.; Neves, M. G. P. M. S.; Cavaleiro, J. A. S.; J. Porphyrins Phthalocyanines 2009, 13, 589; Rebelo, S. L. H.; Pereira, M. M.; Simões, M. M. Q.; Neves, M. G. P. M. S.; Cavaleiro, J. A. S.; J. Catal. 2005, 234, 76.

9. Adolfsson, H. In Modern Oxidation Methods; Bäckvall, J. E., ed.; Wiley: Weinheim, 2004, p. 21-50; Brinksma, J.; de Boer, J. W.; Hage, R.; Feringa, B. L. In Modern Oxidation Methods, Bäckvall, J. E., ed.; Wiley:
Weinheim, 2004, p. 295-326; Jones, C. W.; Applications of Hydrogen Peroxide and Derivatives, The Royal Society of Chemistry: Cambridge, 1999.

10. Ragsdale, R. O.; Vanderhooft, J. C.; Zipp A. P.; J. Chem. Educ. 1998, 75,215 .

11. Gonsalves, A. M. A. R.; Varejão, J. M. T. B.; Pereira, M. M.; J. Heterocycl. Chem. 1991, 28, 635 .

12. Adler, A. D.; Longo, F. R.; Kampas, F. L.; J. Inorg. Nucl. Chem. 1970, $32,2443$.

13. Milgrom, L. R.; The Colours of Life: an Introduction to the Chemistry of Porphyrins and Related Compounds, Oxford University Press: Oxford, 1997.

14. Smith, K. M.; Porphyrins and Metalloporphyrins, Elsevier: Amsterdam, 1975 . 


\section{BIOMIMETIC OXIDATION OF CARBAMAZEPINE WITH HYDROGEN PEROXIDE CATALYZED BY A} MANGANESE PORPHYRIN

Cláudia M. B. Neves, Mário M. Q. Simões*, Fernando M. J. Domingues, M. Graça P. M. S. Neves e José A. S. Cavaleiro Departamento de Química, QOPNA, Universidade de Aveiro, 3810-193 Aveiro, Portugal

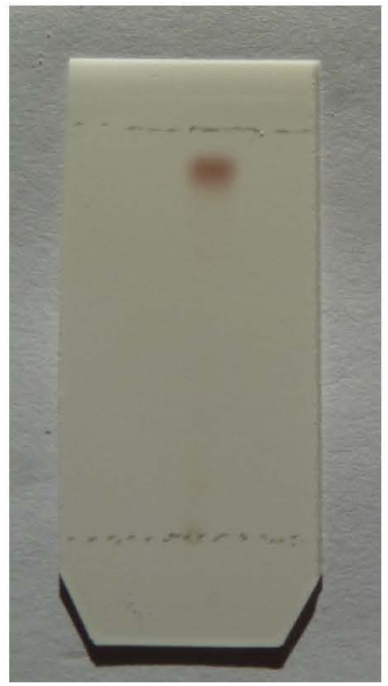

Figure 1S. TLC of the free-base 5,10,15,20-tetrakis(2,6-dichlorophenyl)porphyrin (1) after crystallization using $\mathrm{CH}_{2} \mathrm{Cl}_{2}$ as eluent

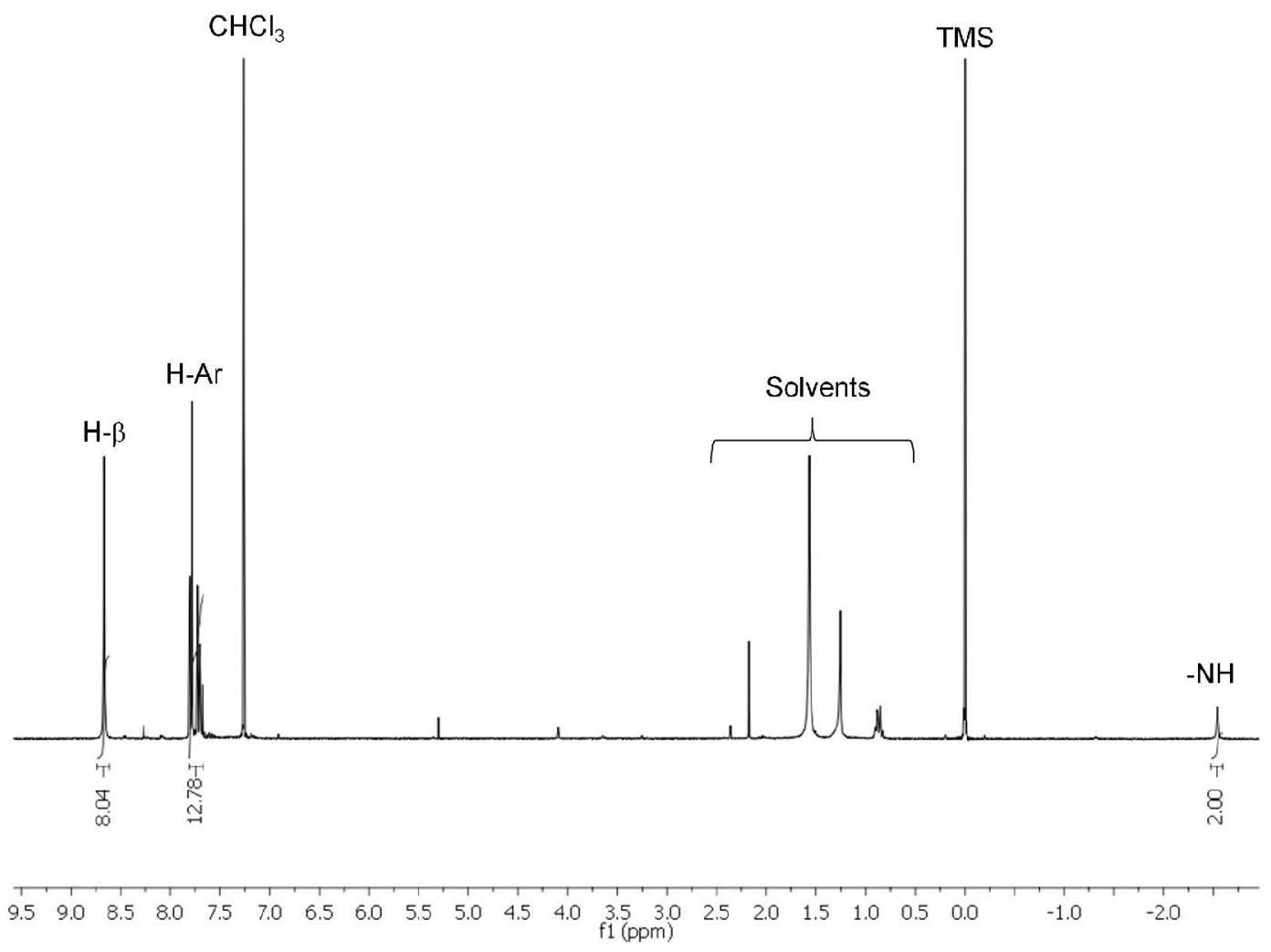

Figure $2 \mathrm{~S} .{ }^{1} \mathrm{H}$ NMR spectrum of the 5,10,15,20-tetrakis(2,6-dichlorophenyl)porphyrin (1) using $\mathrm{CDCl}_{3}$ as solvent 


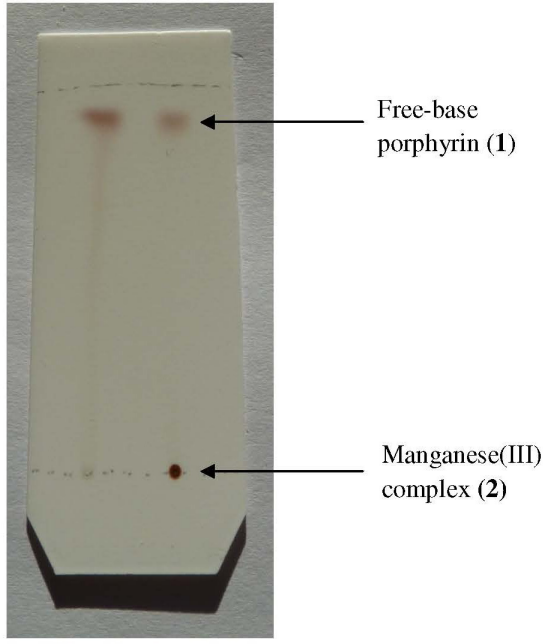

Figure 3S. Monitoring of the reaction progress (session 2) by TLC after one hour. A new red spot of manganese(III) complex (2) can be observed at the base, in contrast with the brown spot of the free-base porphyrin (1) in the top of the TLC plate, using $\mathrm{CH}_{2} \mathrm{Cl}_{2}$ as eluent

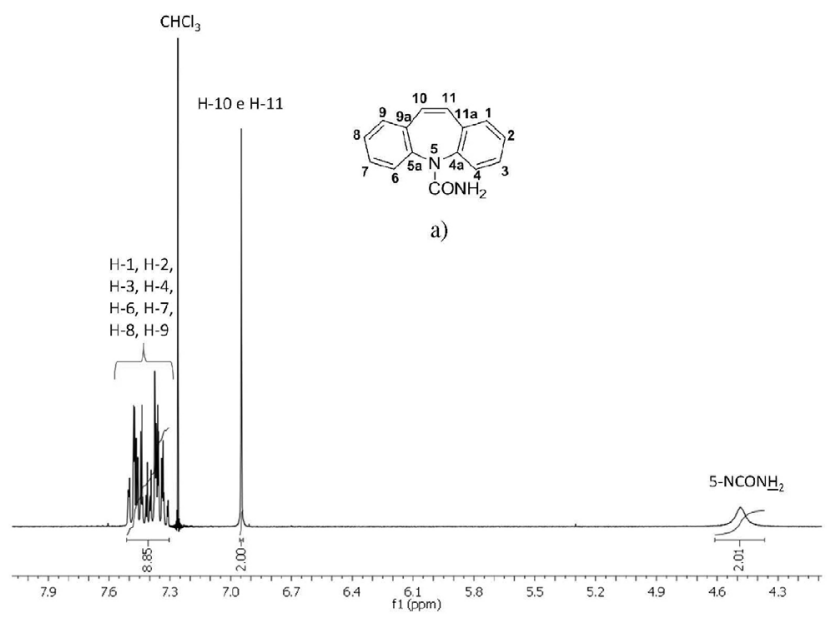

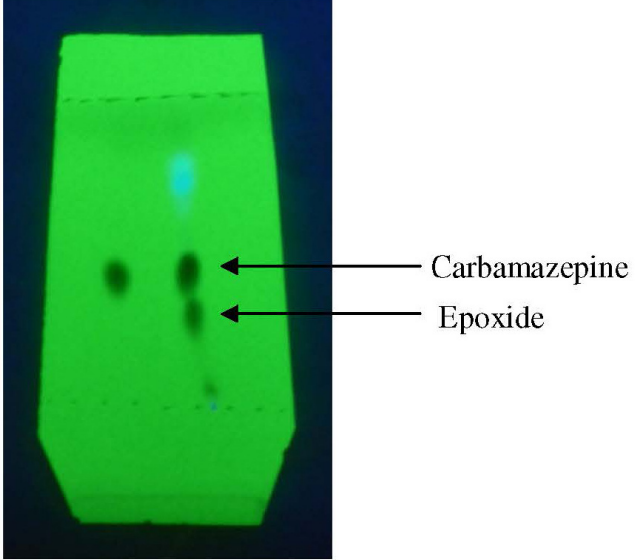

Figure 4S. Picture of the TLC plate obtained after 45 min of reaction (session 3). The carbamazepine spot is at the left and the reaction mixture is at the right, with the formation of a new spot corresponding to the epoxide product, using ethyl acetate as eluent

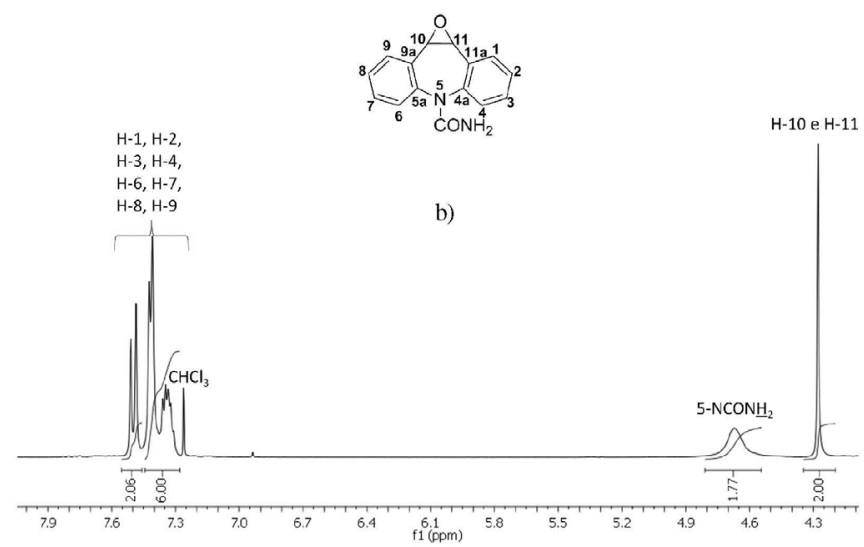

Figure 5S. ${ }^{1} \mathrm{H} \mathrm{NMR}$ spectra $\left(\mathrm{CDCl}_{3}\right)$ of a) carbamazepine (3); b) carbamazepine 10,11-epoxide (4) 